\title{
The Causal Nexus Between Foreign Direct Investment and Economic Growth in Indonesia: An Autoregressive Distributed Lag Bounds Testing Approach
}

\author{
Olivia Tanaya', Suyanto Suyanto ${ }^{1 *}$ \\ ${ }^{1}$ Economics Department, Faculty of Business and Economics, University of Surabaya, Raya Kalirungkut, 60293 Surabaya, \\ Indonesia \\ * Corresponding author, e-mail: suyanto@staff.ubaya.ac.id
}

Received: 07 July 2020, Accepted: 06 November 2020, Published online: 26 November 2021

\begin{abstract}
The nexus between foreign direct investment and economic growth has long been among the most debated issues in macroeconomics. Some studies find a positive link between the two factors, but others find no evidence. This current research fills the gap by analysing the causal nexus between foreign direct investment and economic growth in Indonesia for the period 1970-2018. Indonesia as a developing country is one of the largest recipients of FDI flow; hence the study on the impact of FDI on the economic growth is very much important. This current research employs a contemporary time-series procedure, involving several unit-root tests namely Augmented-Dickey-Fuller (ADF), Phillips-Perron (PP), Kwiatkowski-Phillips-Schmidt-Shin (KPSS), and Lee-Strazicich (LS), an Auto-Regressive-Distributed-Lag (ARDL) bounds-testing method for cointegration, and Granger causality test. The findings provide evidence of long-run and short-run causal direction from GDP to FDI. In contrast, FDI generates only a short-run relationship on GDP. The Granger causality test confirms the finding in ARDL that there is a unidirectional causality running from GDP to FDI.
\end{abstract}

Keywords

foreign direct investment, economic growth, causal relationship, Indonesia

\section{Introduction}

Indonesia is an interesting case for the study of the relationship between foreign direct investment and economic growth. Currently, Indonesia is leading the charge in the ASEAN bloc with its share from the ASEAN's GDP measured at $35.72 \%$ and the World's GDP measured at 3.9\% in 2019 (The Asean Post Team, 2019). The growth rate of Indonesia's Economy has been consistently stable around $5.2 \%$, significantly higher compared to world growth which is $3.2 \%$ (World Development Indicator, 2019). Although it still stands behind the two Asian giants India and China - in growth terms, Indonesia has kept its growth on a stable path even during the Global Financial Crisis of 2008-2009.

One of the most significant factors for increasing economic growth is Foreign Direct Investment (FDI). This investment is crucial, especially when there are insufficient domestic savings. In Indonesia, despite the fact that the average domestic savings rate is still increasing, there have been signs of a constant FDI inflow trend in recent years. Greater FDI inflows are needed to supplement domestic savings. Compare to other sources of international capital, FDI provides advantages as it offers a relatively more stable flow, increases employment and trade, and helps augment productivity capacity (Iamsiraroj and Ulubaşoğlu, 2015).Besides, FDI inflows can play a significant role in increasing the level of competitiveness and development of a country (Kersan-Škabić, 2015). In return, the host country can offer foreign firms a new market, relatively cheap labour, and natural resources. The growing importance of FDI can be observed in Fig. 1 which shows FDI inflows between developed countries, developing countries, and transition countries. Over the past decades, FDI inflows have increased significantly in developing countries.

If we compare the value of FDI between these categories, it shows that the value of FDI in developing countries is more stable than that in developed countries. Moreover, it is stable amidan improving trend. In global FDI inflow terms, Indonesia itself is ranked $18^{\text {th }}$ in 2017 with an aggregate FDI value of 21 billion dollars (UNCTAD, 2019). 


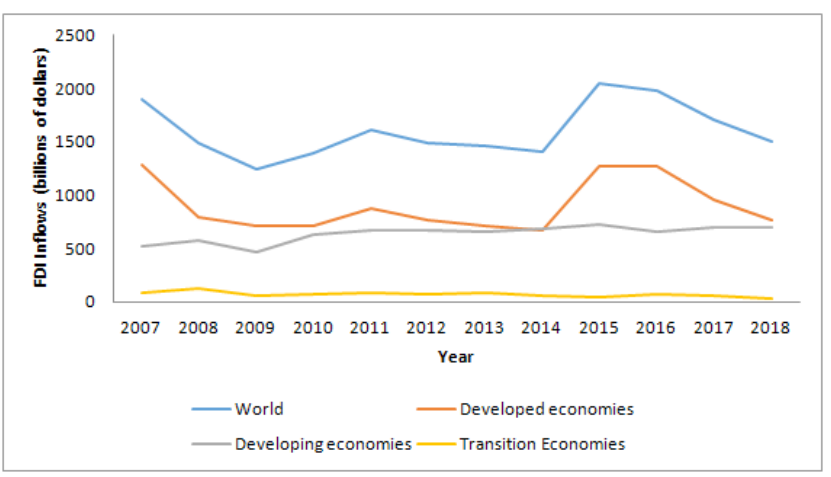

Fig. 1 FDI inflows between developed countries, developing countries, and transition countries, Data source: UNCTAD (2019)

Theoretically, with such a growing trend of FDI, it will induce more economic growth by increasing the country's efficiency and economic productivity ( $\mathrm{Li}$ and Liu, 2005). In turn, it is also possible that economic growth could influence FDI. Economic growth can provide information related to the country economy's performance. When the economy is going strong, it is likely that the companies will generate more profit. A vast majority of research has focused on exploring its effect on economic growth along with economic growth as a location determinant to FDI.

Some studies find out that FDI can increase economic growth with some conditions. Chaudhry et al. (2013); Fifeková and Nemcová (2015) find FDI enhances economic growth in the host country. Nevertheless, it strongly depends on the economic environment of the host country, which can not only absorb the advanced technologies but may also develop them further. The presence of a sufficient level of human capital is also needed in the process of technology diffusion. When the host country has a minimum threshold stock of human capital, FDI will bring more improvements to productivity than domestic investment (Balasubramanyam et al., 1999; Borensztein et al., 1998).

Furthermore, a number of researchers have chosen to focus on the causal relationship between FDI and economic growth. Li and Liu (2005) find a one-way causal relationship from FDI to economic growth, using a large cross-country sample from 1970-1999. An additional finding is that the causal effect of FDI cannot only directly promote economic growth, but can also do this indirectly via its terms of interaction. In contrast, Agrawal (2015) shows a bidirectional relationship between FDI and economic growth. The increasing flows of FDI induces economic growth and vice versa. A more recent study by Iamsiraroj (2016) emphasises the importance of some essential elements, such as a friendly investment climate, openness to trade, and the availability of a labour force in amplifying the effect of FDI on economic growth of the host country.
Some researchers have specifically investigated the relationship between FDI and economic growth in Indonesia, such as Roy and Mandal (2012), who conducted a study over 1981-2008, using a Granger causality test. They found unidirectional causality from economic growth to FDI in Indonesia. Growth-led FDI is more evident due to the large market size that provides opportunities for foreign investors. Recently, Ali and Mingque (2018) have investigated the causal relationship of FDI-economic growth in Asian developing countries (Indonesia, Malaysia, India, Bangladesh) and found that there is no evidence of a causal relationship between FDI and economic growth in the short-run, but that economic growth has a negative and significant impact on FDI in the long-run. The current research extends the previous studies in two respects. Firstly, it employs a long-span time-series dataset from 1970-2018, which provides a comprehensive analysis of causal evidence of growth and FDI in Indonesia. Secondly, this recent study applies a contemporary econometrics method of Auto-Regressive-DistributedLag (ARDL) bounds testing approach, so as to provide a deeper analysis of the FDI-growth nexus.

\section{Literature review}

There are two different perspectives in the theoretical literature on the effect of foreign direct investment on economic growth. These are, respectively, modernisation and dependency theories. Modernisation theory proposes that FDI could generate a positive effect on economic growth in developing countries. This theory is based on the fundamental principle that economic growth needs capital investment (Firebaugh, 1992). Furthermore, modernisation theory is divided into neoclassical and endogenous growth models. In the neoclassical model, the longrun growth could only result from the exogenous factors such as capital accumulation, technological factors, and labour force growth, referred as technological progress (Solow, 1956). FDI could only stimulate economic growth if it permanently enhances technological progress.

While the neoclassical approach focuses on technological progress, the endogenous growth model focuses on knowledge as the basic form of capital. The creation of knowledge will have a positive external effect on the other firm's production possibilities since knowledge cannot be perfectly monopolised. In contrast to capital that has diminishing returns, knowledge does not have any limit boundary (Romer, 1986). Specifically, this theory focuses on investment in human capital (Lucas, 1988). The improvement in human capital will help firms to adapt in the competitive market (França and Rua, 2017) and lead to faster 
innovation. FDI is an important source to gain more knowledge by newer technology and higher capital stock (Anwar and Nguyen, 2010). It also encourages the incorporation of new inputs and technology (Iamsiraroj, 2016). Hence, FDI can stimulate economic growth not only due toits direct effects such as job availability, capital accumulation, and tax income, but also indirectly through the channels from the endogenous growth model.

In contrast with modernisation theory's focus on the positive effects of FDI on economic growth, dependency theory reveals the negative association between the two variables. The core of this theory relies on the concepts of centre and periphery. Sophisticated industries are located in the centre, while in the periphery the industries are limited to, for example, the production of the raw material for the industries in the centre. The industries in the periphery are prevented from achieving capital accumulation. Rather than being used to develop the periphery, accumulated capital is transmitted to the centre (Amin, 1974). Foreign capital only delivers a limited transmission of technology; consequently, it cannot help to build up the economies of the host. Further, the theory argues that dependency on foreign investment will bring a negative effect on economic development, impacting economic growth and income distributions especially. This is due to the fact that the multiplier effect from the demand elasticity between two sectors is weak, and thereby brings about stagnant growth in the developing countries (Adams, 2009).

\section{Source data and method of analysis}

This study uses annual data from 1970-2018 and E-views 11 software to analyse the relationship between two variables, Growth Domestic Product (GDP) and Foreign Direct Investment (FDI) in Indonesia. The data was collected from the World Bank's World Development Indicator. GDP is the sum of gross value added by all resident producers in the economy, plus any product taxes and minus any subsidies not included in the value of the products. The data is measured in constant 2010 U.S. dollars. In the meantime, FDI is measured as direct investment equity flows into the reporting economy (net inflow), converted into a real unit by applying a GDP deflator. All data has been converted into a natural logarithm.

For the first step of time-series analysis, several unit root tests are applied to check the data series. Auto-RegressiveDistributed-Lag (ARDL) bounds testing approach is then performed to estimate the existence of cointegration between the variables. The results from cointegration test determine that proper model for the long-term equilibrium relationship. When a cointegration does exist between the variables, an Error Correction Model (ECM) is performed to examine the short-term relationship. In contrast, if the cointegration test suggests no-cointegration, the short-run relationship is pictured in the first order ARDL. After confirming the long-run and the short-run relationships, causality analysis under Granger test is conducted. Finally, several diagnostic tests are performed for checking robustness.

\subsection{Unit root tests}

When modelling time-series data, it is important to check whether the variables are stationary or non-stationary series. A stochastic process is said to be stationary if the mean and variance are constant, and the value of autocorrelation is time invariant. ${ }^{1}$ The reverse situation might occur in the non-stationary series. The existence of non-stationary series could cause spurious regression that leads to incorrect inferences (Granger, 2003). The series should be stationary as spurious result means there is a highly significant of $t$-ratio and high value of $R^{2}$, but the tested variables have no interrelationships (Chaudhry et al., 2013). If all variables are stationary series, a regular econometric model such as regression is an appropriate model. While if there is non-stationary series in data, other methodology should be applied. When non-stationary series becomes stationary after being differenced $d$ times, then the variable is said to be integrated of order $d$, denoted $I(d)$. The series is said to be integrated of order one if it takes first difference to achieve stationarity. The series is said to be integrated of order two if it has to be differenced twice to achieve stationarity, and so on. In addition, the uses of ARDL bounds testing required no variables are integrated in order two or $I(2)$. It is essential to check the variables are in $I(0)$ or $I(1)$, otherwise, the presence of $I(2)$ would invalidate the methodology. This present study conducts several unit-root tests, namely Augmented Dickey-Fuller (ADF), PhillipsPerron (PP), Kwiatkowski-Phillips-Schmidt-Shin (KPSS), and Lee-Strazicich (LS) unit root tests.

\subsubsection{Augmented Dickey-Fuller (ADF) test}

The ADF test allows for higher-order autoregressive processes by added $\Delta Y_{t-i}$ as an explanatory variable in the model to detect any autocorrelation (Dickey and Fuller, 1981). The null hypothesis is there is a unit root $\left(\beta_{1}=0\right)$. If the null hypothesis is not rejected, then the

$\mathbf{1}$ This stochastic process in the time series literature is known as a weakly stationary. In most practical situations, this type of stationarity often suffices. 
series is non-stationary. There are three variants of the ADF test, depending on whether the model should include constant or trend. The three models are presented as followed:

1. Test with no constant and no trend:

$$
\Delta Y_{t}=\beta_{1} Y_{t-1}+\sum_{i=1}^{n} \alpha_{1} \Delta Y_{t-i}+\varepsilon_{t}
$$

2. Test with constant and no trend:

$$
\Delta Y_{t}=\beta_{0}+\beta_{1} Y_{t-1}+\sum_{i=1}^{n} \alpha_{1} \Delta Y_{t-i}+\varepsilon_{t}
$$

3. Test with constant and trend:

$$
\Delta Y_{t}=\beta_{0}+\beta_{1} Y_{t-1}+\beta_{2} t+\sum_{i=1}^{n} \alpha_{1} \Delta Y_{t-i}+\varepsilon_{t}
$$

where $\Delta Y_{t}$ is the first difference of the dependent variable, $\varepsilon_{t}$ is the white nose error term. A plotting of the time-series is carried out to choose a suitable ADF test. If the data series appears to be fluctuating around a sample average of zero, the more appropriate model is model (Eq. (1)). In contrast, if the data series appears to be fluctuating around a sample average which is non-zero, model (Eq. (2)) is wellsuited. Furthermore, if the data series appears to be fluctuating around a linear trend, one can apply model (Eq. (3)) (Hill et al., 2011).

\subsubsection{The Phillips-Perron (PP) test}

Phillips and Perron have developed a more comprehensive theory of unit root stationary. They use a non-parametric approach with respect to nuisance parameters, hence, it allows for wide class of weakly dependent and possibly heterogeneous data (Phillips and Perron, 1988). This test incorporates an automatic correction to the DF test to allow auto-correlated residuals (Brooks, 2014). These modified statistics, as denoted by $Z_{t}$ and $Z_{\delta}$ are calculated as:

$$
\begin{aligned}
& Z_{t}=\sqrt{\frac{\hat{\alpha}^{2}}{\hat{\beta}^{2}}} t_{\hat{\delta}}-\frac{1}{2}\left(\frac{\hat{\beta}^{2}-\hat{\alpha}^{2}}{\hat{\beta}^{2}}\right)\left(\frac{T(S E(\hat{\delta}))}{\hat{\alpha}^{2}}\right) \\
& Z_{\delta}=T \hat{\delta}-\frac{1}{2} \frac{T^{2}(S E(\hat{\delta}))}{\hat{\alpha}^{2}}\left(\hat{\beta}^{2}-\hat{\alpha}^{2}\right)
\end{aligned}
$$

The terms $\hat{\alpha}^{2}$ and $\hat{\beta}$ are consistent estimates of the variance parameters:

$$
\alpha^{2}=\lim _{T \leftarrow \infty} T^{-1} \sum_{t=1}^{T} E\left(\varepsilon_{t}^{2}\right)
$$

$$
\beta^{2}=\lim _{T \rightarrow \infty} \sum_{t=1}^{T} E\left(\frac{1}{T} \sum_{t=1}^{T} \varepsilon_{t}^{2}\right)
$$

where $T$ denotes the sample size and $S E(\hat{\delta})$ is standard error of $(\hat{\delta})$. Under the null hypothesis $\delta=0$, the asymptotic distribution of the $\operatorname{PP} Z_{t}$ and $Z_{\delta}$ is same as with the ADF test statistic and normalised bias statistics.

\subsubsection{Kwiatkowski-Phillips-Schmidt-Shin (KPSS) test}

Kwiatkowski et al. (1992) propose a unit root test under the null hypothesis that an observable series is stationary around a deterministic trend. The unit root is tested in the alternative hypothesis, unlike the null hypothesis of other unit root tests. The series itself is expressed by the combination of deterministic trend, random walk, and stationary test. The test is using Lagrange Multiplier (LM) statistic for the stationary hypothesis. KPSS test takes the following model:

$Y_{t}=\alpha_{0}+\alpha_{1} t+r_{t}+\varepsilon_{t}$

where $r_{t}$ is a random walk:

$r_{t}=r_{t-1}+u_{t}, u_{t} \sim \operatorname{IID}\left(0, \sigma_{u}^{2}\right)$.

Equation (8) has three different components. Firstly, deterministic components which expressed by $\alpha_{0}$ for a constant term and $\alpha_{1} t$ for a linear time trend. Secondly, $r_{t}$ is either a random walk component or a constant term, which depends on the value of $u_{t}$, denoted as $\sigma_{u}^{2}$, whether it has non-zero value or not. Lastly, $u_{t}$ is disturbance term, and by assumption is a series of independent and identically distributed random variables that has expected value equals to zero and constant variation $\sigma_{u}^{2}$. The null hypothesis is $\sigma_{u}^{2}=0 \rightarrow Y_{t} \sim I(0)$ against the alternative hypothesis $\sigma_{u}^{2}>0 \rightarrow Y_{t} \sim I(1)$. Under some assumption (normality and IID for $\epsilon_{t}$ and $u_{t}$ ), the KPSS test or a one-sided LM test can be constructed by:

$\mathrm{LM}=\frac{1}{T^{2}} \frac{\sum_{t=1}^{T} S_{t}^{2}}{\hat{\sigma}_{\varepsilon}^{2}}$

where $S_{t}=\sum_{i=1}^{t} e_{i}$ and let $e_{t}, t=1,2, \ldots, T$ be the residuals obtained by regressions of $y$ on an intercept and time trend. In addition, $\hat{\sigma}_{\varepsilon}^{2}$ in the Eq. (10) is the estimate of the error variance from this regression (the sum of squared residuals divided by $T$ ). 


\subsubsection{Lee-Strazicich (LS) test}

A structural break often occurs in time-series data due to policy changes, regime shift, economic crisis, and changes in institutional arrangements. In recent times, the question of how to identify a structural break becomes one of the most important considerations when analysing time-series data. Some data series may have structural breaks either in the slope or in the intercept, or breaks can be found in both the slope and the intercept. Hence, it is important to apply a unit root test which can take into account the structural breaks in the data series. Lee and Strazicich (2003) proposed a two-break minimum LM unit root test in which the alternative hypothesis unambiguously implies trend stationarity. This test allows for structural breaks under the null hypothesis $\beta=1$ and alternative hypothesis $\beta<1$ in a consistent manner. Consider the Data Generating Process (DGP) as follows:

$$
y_{t}=\delta^{\prime} Z_{t}+e_{t}, e_{t}=\beta e_{t-1}+\varepsilon_{t}
$$

where $\boldsymbol{Z}_{t}$ is a vector of exogenous variable, and $\varepsilon_{t}$ is an error term with assumption IID $N\left(0, \sigma_{u}^{2}\right)$. There are two models developed, the first one, Model A (is known as crash model) which allows for two shift in level and is described by $\boldsymbol{Z}_{\boldsymbol{t}}=\left[1, t, D_{1 t}, D_{2 t}\right]^{\prime}$ where $\boldsymbol{Z}_{\boldsymbol{t}}$ is a vector variable, $t$ is time trend, and $D_{j t}$ is a dummy variable defined as $D_{j t}=1$ for $t \geq T_{B j}+1, j=1,2$, and zero otherwise, and $T_{B j}$ denotes time period of breaks. The other is Model C (known as break model) which allows for two shifts in both level and trend and is described by $\boldsymbol{Z}_{t}=\left[1, t, D_{1 t}, D_{2 t}, D T_{1 t}, D T_{2 t}\right]^{\prime}$ where $D T_{j t}=t-T_{B j}$ for $t \geq T_{B j}+1, j=1,2$, and zero otherwise. The process of $y_{t}$ in the crash model can be formulated as follows:

Null: $y_{t}=\mu_{0}+d_{1} B_{1 t}+d_{2} B_{2 t}+y_{t-1}+v_{1 t}$

Alternative: $y_{t}=\mu_{0}+\gamma_{t}+d_{1} D_{1 t}+d_{2} D_{2 t}+v_{2 t}$

In the Eqs. (12) and (13), $B_{j t}=1$ for $t=T_{B j}+1, j=1,2$, and zero otherwise. Both $v_{1 t}$ and $v_{2 t}$ are stationary error terms. While for break model, the terms $D_{j t}$ is added at Eq. (12) and the terms $D_{j t}$ is added at Eq. (13). Under the null hypothesis, it is assumed that $d_{1}=d_{2}=0$.

The two-break LM unit root test statistic is obtained by following regression:

$$
\Delta y_{t}=\delta^{\prime} \Delta \boldsymbol{Z}_{t}+\theta \bar{S}_{t-1}+\mu_{t}
$$

where the de-trended series $\bar{S}_{t}$ is defined by: $\bar{S}_{t}=y_{t}-\psi_{x}-\boldsymbol{Z}_{\boldsymbol{t}} \tilde{\delta}, t=2, \ldots, T, \tilde{\delta}$ equals the coefficients in the regression of $\Delta y_{t}$ onto $\Delta Z_{t}$ and $\psi_{x}$ equals $y_{1}-Z_{1} \tilde{\delta}$, where $y_{1}$ and $Z_{1}$ correspond to the first observations of $y_{t}$ and $Z_{t}$ respectively. The unit root null is described by $\phi=0$. The LM test statistics is as $\tilde{p}=T \tilde{\phi}$ and $\tilde{\tau}$ is the $t$-statistics for test the unit root null. The location of structural breaks $\left(\lambda_{j}=T_{B j} / T, j=1,2\right.$ is determined by utilising a grid search as follows:

$$
\begin{aligned}
& \mathrm{LM}_{p}={ }_{\lambda}^{\inf } \tilde{p} \lambda \\
& \mathrm{LM}_{\tau}={ }_{\lambda}^{\inf } \tilde{\tau} \lambda .
\end{aligned}
$$

As is typical for an endogenous break test, to eliminate endpoints the trimming process is utilised over the trimming region $0.1 T$, where $T$ is the sample size.

\subsection{ARDL bounds testing approach to cointegration analysis}

For testing the long-run relationship, there are several cointegration techniques can be adopted. The most common techniques are Engle and Granger (1987), Johansen (1988) and Johansen and Juselius (1990). The new cointegration technique is ARDL bounds testing proposed by Pesaran et al. (2001). Compared with the other cointegration techniques, ARDL bounds testing has some advantages, such as:

1. It is very flexible in terms of its application. The techniques can be applied to variables that have different order of integration as long as the variables are $I(0)$ and $I(1)$.

2. It is suitable not only in the large sample but also in the small sample.

3. The uses of ARDL bounds testing is simple due to its single equation set.

4. It can deduce the dynamic error correction. The general error correction model includes the error lag term in the long-run model. In the ARDL bounds testing, different lag terms can be applied for different variables.

5. The endogeneity problem and autocorrelation are fully solved (Zhang and Zhang, 2018).

Based on the advantages and the sample size of this research, this research uses ARDL bounds testing to analyse the relationship between GDP and FDI in Indonesia. The equation to reveal the long-run relationship is as follows: 


$$
\begin{aligned}
& \Delta \ln \mathrm{GDP}_{t}=a_{1}+\sum_{i=1}^{m} b_{1} \Delta \ln \mathrm{GDP}_{t-i} \\
& +\sum_{i=0}^{n} b_{2} \Delta \ln \mathrm{FDI}_{t-i}+c_{1} \ln \mathrm{GDP}_{t-1} \\
& +c_{2} \ln \mathrm{FDI}_{t-1}+d_{1} D_{t}+\varepsilon_{t}
\end{aligned}
$$

where $b_{1}$ and $b_{2}$ represent the short run dynamic relationship, $c_{1}$ and $c_{2}$ represent the long run dynamic relationship. $D_{t}$ is the dummy variable to account the structural break $m$ and $n$ $(i=1,2,3,4,5)$ are the lag period for the explained variable and each explanatory variable. The white noise error term is expressed by $\varepsilon_{t}$. ARDL bounds testing uses $F$-statistic for the joint significance of the coefficients to test if there is long run relationship or cointegration. The null hypothesis is $c_{1}=c_{2}$, which indicated that there is no long run relationship / no cointegration. Besides using $F$-statistic, this model also includes a $t$-statistic of the lagged dependent variables to check the cointegration relationship.

Pesaran et al. (2001) provides two sets of critical value bonds for the $F$-statistic: one set is used when all the variables are $I(0)$ and the other set is used when the variables are purely $I(1)$. If the value of the $F$-statistic or $t$-statistic is greater than upper bound of critical value, the null hypothesis is rejected, and there is long run relationship between the variables. On the other hand, if the value of the $F$-statistic is lower than the lower bound of critical value, the null hypothesis cannot be rejected, and there is no long run relationship between the variables. Finally, if the value of $F$-statistic is between the two critical values, then it cannot be judged whether there is long run relationship among the variables. Besides the critical value from Pesaran et al. (2001), we also use additional critical value from Narayan (2005). The critical value from Narayan (2005) can be used for small sample size with range 30 until 80 observations.

Short run dynamic relationships are applied by using the Error Correction Model (ECM) as stated below:

$$
\begin{aligned}
& \Delta \ln \mathrm{GDP}=a_{2}+\sum_{i=1}^{m} e_{1} \ln \mathrm{GDP}_{t-i}+\sum_{i=0}^{n} e_{2} \ln \mathrm{FDI}_{t-i} \\
& +\tau \mathrm{ECT}_{t-1}+\mu_{t}
\end{aligned}
$$

where $e_{s}$ shows short run dynamics, ECT denotes error correction terms measuring the speed of adjustment toward long run equilibrium after a short run shock. The expected value of the coefficient of ECT $(\tau)$ is between -1 and 0 , where -1 implies perfect convergences and 0 implies no convergence. The ECT must be significant to show the convergences did exist (Rahman and Kashem, 2017). If the value of ECT is negative but insignificant, it indicates that the result is inconclusive.

\subsection{Diagnostic tests of the model}

One of the important assumptions in ARDL bounds test are the residuals are serially uncorrelated and homoscedastic. We apply several diagnostic tests to ensure the result is reliable. First, we apply the Breusch-Godfrey Serial Correlation Langrange Multipler (LM) test to check for serial correlation (Brooks, 2008). This test can detect autocorrelation in dynamic models. It allows up to the $r^{\text {th }}$ order. The model for the error, as follows:

$v_{t}=\rho_{1} v_{t-1}+\rho_{2} v_{t-2}+\ldots+\rho_{r} v_{t-r}+\varepsilon_{t} \varepsilon_{t} \sim N\left(0, \sigma_{\varepsilon}^{2}\right)$.

The null hypothesis is $\rho_{1}=0$ and $\rho_{2}=0$ and $\rho_{r}=0$ (no autocorrelation). The test statistic $(T-r) R^{2} \sim \chi_{R}^{2}$ asymptotically distributed, where $T$ is number of observations in the basic series, and $r$ is the number of lags of the error terms.

Second, Bresuch-Pagan-Godfrey is applied to check the heteroscedasticity. Derived from LM test principle, it tests whether the variance of the errors from a regression is dependent on the values of the independent variables. In this situation, heteroscedasticity is present. It estimates a linear regression model and obtains a set value of residuals $\hat{u}_{1}, \hat{u}_{2}, \ldots, \hat{u}_{n}$. In order to test the variance of the errors, this test features an auxiliary regression equation as follows:

$\hat{u}_{i}^{2}=\gamma_{1}+\gamma_{2} Z_{2 i}+\gamma_{3} Z_{3 i}+\ldots+\gamma_{p} Z_{p i}+v_{i}$.

The null hypothesis is $\gamma_{1}=\gamma_{2}=\ldots=\gamma_{p}=0$. In contrast, the alternative hypothesis is that at least one of $\gamma_{s}$ is different from zero.

Last, we apply a Jarque-Bera normality test for testing normality of the error of the models. The idea of this test is to check whether the coefficient of skewness and the coefficient of excess kurtosis are jointly zero. A normal distribution is not skewed and has coefficient of kurtosis less than 3. Skewness is denoted as $S$, and kurtosis is denoted as $K$ :

$S=\frac{E\left(u^{3}\right)}{\left(\sigma^{2}\right)^{3 / 2}}$ and $K=\frac{E\left(u^{4}\right)}{\left(\sigma^{2}\right)^{2}}$.

The Jarque-Bera test is given by:

$$
\mathrm{JB}=T\left[\frac{S^{2}}{6}+\frac{(K-3)^{2}}{24}\right]
$$

where $T$ is the sample size. The test asymptotically follows a $\chi^{2}(2)$ under the null hypothesis that is a combination of hypotheses that skewness is zero and excess kurtosis is also zero. 


\subsection{Stability tests of the model}

The classical linear regression model has the implicit assumption that the appropriate "functional form" is linear. However, this assumption may not always be upheld. In order to check whether the model held the assumption, it can be test by using Ramsey RESET test, a test to check a model specification. This method works by combining higher order terms of fitted value (e.g. $\hat{y}_{t}^{2}, \hat{y}_{t}^{3}$, etc.) and the original explanatory variables into auxiliary regression.

$$
y_{t}=\beta_{1}+\beta_{2} \hat{y}_{t}^{2}+\beta_{3} \hat{y}_{t}^{3}+\ldots+\beta_{n} \hat{y}_{t}^{n}+\sum \alpha_{i} x_{i t}+v_{t}
$$

Higher order powers of $y$ can capture other form of non-linear relationships, since they embody cross-product and higher order powers of the original explanatory.

$$
\hat{y}_{t}^{2}=\left(\hat{\alpha}_{1}+\hat{\alpha}_{2} x_{2 t}+\hat{\alpha}_{3} x_{3 t}+\ldots+\hat{\alpha}_{n} x_{n t}\right)^{2}
$$

The test statistic is given by $T R^{2}$, the value of $R^{2}$ is from the Eq. (23). It is distributed asymptotically as a $\chi^{2}(p-1)$.

The stability of the model is tested under the cumulative sum of recursive residuals (CUSUM) and the cumulative sum of recursive residuals of squares (CUSUMSQ). Page (1954) uses a quality number, $\theta$, to measure a parameter of distribution. He devised CUSUM as a tool to measure the changes in $\theta$, and constructed a criterion for deciding when to take corrective action. Under the null hypothesis of parameter stability, the CUSUM statistic is zero; however, many residuals will appear in the sum (due to the expected value of a residual always being zero). The rule of CUSUM applies when the cumulative score is plotted on a chart, and the value of change is constant and less than 5\%.

The CUSUMSQ is a complement to test the parameter stability, especially when the value of change is haphazard rather than systematic (Brown et al., 1975). Under the null hypothesis of parameter stability, the CUSUMSQ will begin at zero and end the sample at 1 . The value of CUSUMSQ need to be between $5 \%$ critical bounds to indicate parameter stability.

\subsection{Granger causality}

If there is cointegration between two or more time-series, then there is a potential Granger causality between them, either unidirectional or bidirectional (Rahman and Kashem, 2017). We need to apply a causality test in order to know the direction of the causality. Granger (1969) shows whether $X$ causes $Y$ by testing how much the current $y$ can be predicted by using the value of past $Y$ and the lagged of $X$. We can say that $Y$ Granger-caused by $X$ if $X$ can help to determine the value of current $Y$ or if the coefficient on the lagged of $X$ are statistically significant. We use the following model to examine the Granger causality between GDP and FDI:

$Y_{t}=\mu_{0}+a_{1} Y_{t-1}+\ldots+a_{p} Y_{t-p}+b_{1} X_{t-1}+\ldots+b_{p} X_{t-p}+u_{t}$

where $a_{1}$ to $a_{p}$ and $c_{1}$ to $c_{p}$ represent the coefficient for the lagged dependent variable, and $b_{1}$ to $b_{p}$ and $d_{1}$ to $d_{p}$ represent the coefficient for the lagged of independent variable. Note that the series are in the level from and not in the difference form. The $u_{t}$ and $v_{t}$ are white noise error terms, and these errors should be zero in the long run equilibrium.

The procedure of Granger causality is estimate by using vector autoregression (VAR). We need to determine the maximum number of lags by applying VAR lag techniques. The usual information criteria such as AIC or SC becomes the basis to choose the lag length. Then, the null hypothesis for Eq. (25) is $b_{1}=b_{2}=\ldots=b_{p}=0$ which indicate $X$ does not Granger cause $Y$ against the alternative hypothesis that $X$ Granger causes $Y$.

\section{Findings and analysis}

\subsection{Summary statistics of the main variables}

The summary statistics of the main variables is presented in Table 1. The GDP variable has a mean value 26.5802, with a minimum value 25.2078. Accordingly, FDI has a mean value 16.8629 and a minimum value zero. The minimum value of FDI can be zero due to the net FDI inflows in 1998 to 2000 that are negative in values (as displayed in Fig. 2). To normalise the data series, the missing values because of the natural logarithm transformation are converted into zero. The negative values of the net FDI inflows in the period 1998-2000 are mainly due to the Asian crisis at that time, with Indonesia being the third worst hit country in the region (IMF, 1998). The uncertain political situation in 1998 (known as May 1998 riots or tragedy) has amplified the effect of economic crisis, which resulted in a drastic devaluation of the rupiah, a large withdrawal of credit from the lenders, and a significant outflow of FDI from Indonesia.

The last column of the Table 1 shows the probability value of Jarque-Bera (J.B) test. As for the GDP variable, the probability value is 0.2922 , which is larger than the $5 \%$ level, suggesting a normal distribution of GDP. In contrast,

Table 1 Summary statistics of the main variables

\begin{tabular}{lcccccc}
\hline \multirow{2}{*}{ Series } & \multirow{2}{*}{ Mean } & $\begin{array}{c}\text { Std. } \\
\text { Error }\end{array}$ & Min. & Max. & J.B & $P$-value \\
\hline GDP & 26.5802 & 0.7287 & 25.2078 & 27.7680 & 2.4610 & 0.2922 \\
FDI & 16.8629 & 5.8226 & 0.0000 & 20.8650 & 92.5635 & 0.0000 \\
\hline
\end{tabular}

Note: The data are transformed into natural logarithm. 


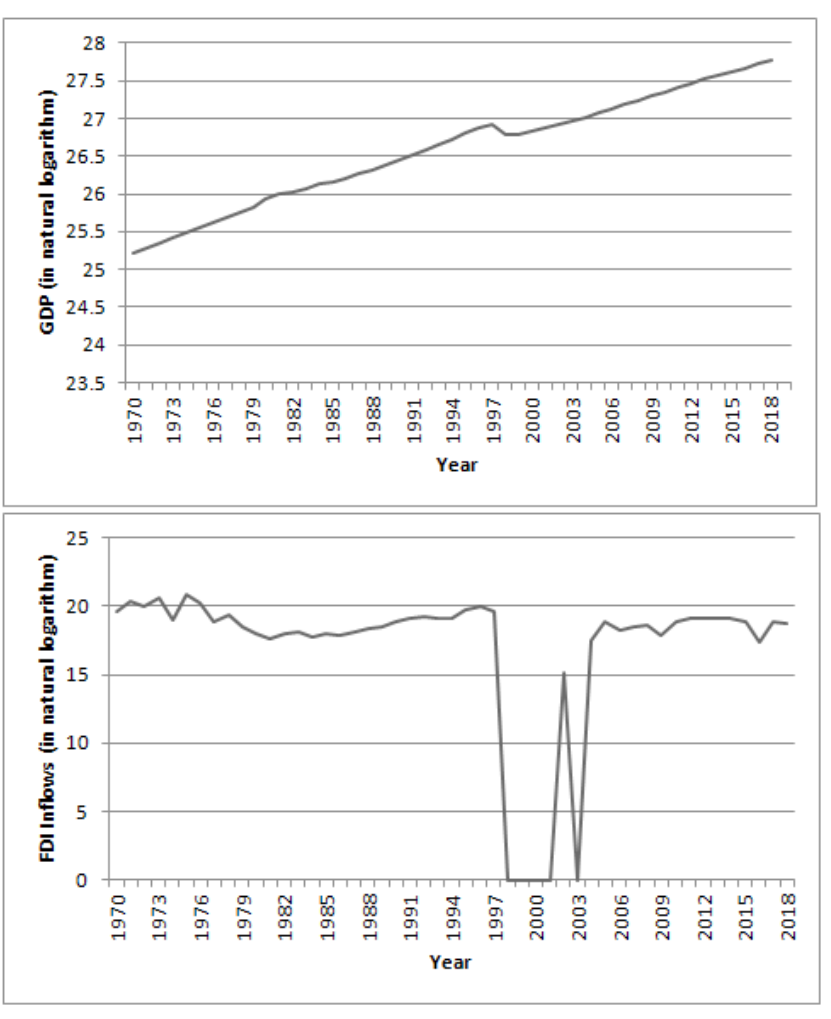

Fig. 2 GDP and FDI in Indonesia from 1970-2018 (The original data for GDP are in constant 2010 US\$ while FDI are in millions US\$, data are transform into natural logarithm), Data source: World Development Indicator (2019)

the probability value of FDI variable is approaching zero, which indicate the rejection of the null hypothesis of J.B that the data is normally distributed.

In other words, the FDI data is not normally distributed. These findings conclude that the two data-series have different distributions, which leads to the usage of a proper methodology to deal with the data, as performed below.

\subsection{Findings of the unit root test}

Before applying the unit root test, a plotting of the time series variables is performed to track the existence of trend in the data-series. As shown in Fig. 2, GDP data do exhibit a trend, suggesting that an appropriate unit root model is the trend model. In contrast, the FDI data-series fluctuates around the average, suggesting the characteristic of a constant without any trend. The results of unit root tests under several methods, namely ADF, PP, KPSS, and LS, are presented in Table 2.

From the results in Table 2, GDP series is non-stationary at level but stationary at first difference, as indicated by the significance of the series at $1 \%$ under ADF, PP, and LS methods. In contrast, the FDI series is stationary at level. The mix order of stationary confirms the findings of the JB-test that the two-series have two different distributions. The difference in data distribution justifies the uses of ARDL bounds testing for the two series.

Additional information that can be drawn from Table 2 is that the GDP and FDI series have two possible breaks, in 1998 and in 2006. The break in 1998 is due to the Asian financial crisis, as previously discussed. While for 2006, the break there is mainly due to a high increase in the world oil price, which reached its highest level in 25 years (around \$70 dollar per barrel) and triggered a medium level of inflation in Indonesia - it rose up to $17.1 \%$ (Indonesian Central Bank, 2006).

\subsection{ARDL model estimation}

In order to perform the ARDL method, one needs to determine the optimum lag length for the Eq. (17). In this research, the order of lag is selected under the Schwarz

Table 2 Unit root test results

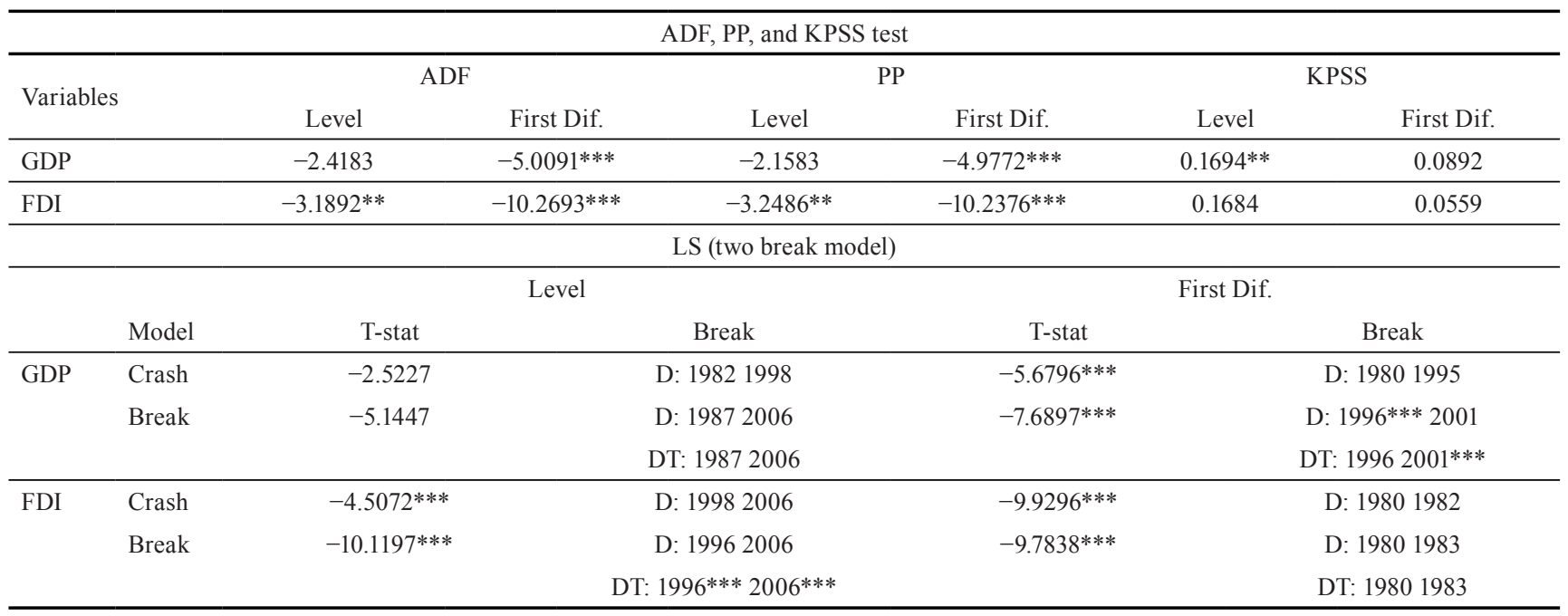

Note: $* *, * * *$ indicates the significance level of $5 \%$, and $1 \%$. 
Bayesian Criterion (SBC). For the equation with GDP as the dependent variable (model 1), the SBC result suggests that the optimum order of lag is $m=2 ; n=0$. Subsequently for the equation with FDI as the dependent variable (model 2 ), the $\mathrm{SBC}$ result suggests the optimum order of lag is $m=2 ; n=1$.

In addition, the model for GDP as dependent variable is a "constant and trend" equation, whereas the model for FDI as dependent variable is "constant" equation. The equations are chosen based on the best results in diagnostic tests.

Table 3 shows the result of long run estimation of ARDL model following the well-suited lag-length as indicated in SBC results. The Dum_1998 is the dummy variable for the first break of economic crisis, which have a value of 1 for the year 1998 and zero for the other years. The Dummy_2006 represent the second break picturing the shock in oil price, which takes a value of 1 for year 2006 and zero for other years. Both in model 1 and model 2, the dummy of 1998 has a negative value and statistically significant. These findings indicate that the economic crisis 1998 did significantly affect GDP and FDI of Indonesia.

On the other hand, Dum_2006 was not statically significant in both models. This implies that although the shock oil price in 2006 decreased the value of GDP and FDI, its effect was nonetheless not significant. Both the coefficient

Table 3 Estimates of long-run ARDL model

\begin{tabular}{|c|c|c|c|}
\hline $\begin{array}{l}\text { Dependent } \\
\text { variable }\end{array}$ & Regressors & Coefficient & $t$-statistic \\
\hline \multirow{10}{*}{$\begin{array}{l}\Delta \operatorname{lnGDP} \\
\text { (Model 1) }\end{array}$} & $\operatorname{lnGDP}_{-1}$ & 1.1813 & $14.6976^{* * *}$ \\
\hline & $\operatorname{lnGDP}_{-2}$ & -0.1942 & $-2.5333^{* *}$ \\
\hline & $\operatorname{lnFDI}$ & 0.0006 & 1.2615 \\
\hline & Dum_1998 & -0.183 & $-10.9449 * * *$ \\
\hline & Dum_2006 & -0.0026 & -0.1844 \\
\hline & $C$ & 0.3707 & 0.5445 \\
\hline & Trend & 0.0004 & 0.2759 \\
\hline & $R$-squared: & 0.9997 & \\
\hline & $\begin{array}{c}\text { Adjusted } \\
R \text {-squared: }\end{array}$ & 0.9996 & \\
\hline & $F$-statistic: & 20069.47 & \\
\hline \multirow{10}{*}{$\begin{array}{l}\Delta \operatorname{lnFDI} \\
(\text { Model 2) }\end{array}$} & $\operatorname{lnFDI}_{-1}$ & 0.0885 & $3.2770 * *$ \\
\hline & $\ln \mathrm{FDI}_{-2}$ & 0.0500 & $1.8633^{*}$ \\
\hline & $\operatorname{lnGDP}$ & 11.4413 & $2.5110 * *$ \\
\hline & $\operatorname{lnGDP}_{-1}$ & -11.5212 & $-2.5525^{* *}$ \\
\hline & Dum_1998 & -16.5540 & $-28.2534 * * *$ \\
\hline & Dum_2006 & -0.4847 & -0.6183 \\
\hline & $C$ & 17.6938 & $3.6367 * * *$ \\
\hline & $R$-squared: & 0.9853 & \\
\hline & $\begin{array}{c}\text { Adjusted } \\
R \text {-squared: }\end{array}$ & 0.9831 & \\
\hline & $F$-statistic: & 446.3018 & \\
\hline
\end{tabular}

Note: $* * *, * * *$ indicates the significance level of $10 \%, 5 \%$, and $1 \%$. of FDI in model 1 and the coefficient of GDP in model 2 are positive, which indicate that higher FDI will induce higher economic growth and higher economic growth will attract FDI. To check the existence of a long run relationship, ARDL bound-test is performed on the F-statistic and the $t$-statistic of the lagged dependent variables.

Table 4 presents the ARDL bound test, both the statistical values and the critical values. The critical value is based on table CI(v) for model 1 and table CI(iii) for model 2, following Pesaran et al. (2001). Another set of critical values are taken from Narayan (2005). For model 1, the value of $F$-statistic and $t$-statistic is lower than all critical values. It shows that there is no indication of cointegration between variables in the model. On the other hand, the values of the $F$-statistic and $t$-statistic in model 2 exceed the upper critical value at a $1 \%$ level of significance from both Pesaran et al. (2001) and Narayan (2005) $)^{2}$. It implies that there is cointegration or a long-run relationship between variables in model 2. Findings from the ARDL bound test in the two models suggesting the existence of a long-run relationship from GDP to FDI, whereas there is no evidence of a long-run relationship from FDI to GDP.

\subsection{Findings of short-run dynamic relationship}

The short-run dynamic relationship can be analysed through two approaches. An Error Correction Model (ECM) is employed when there is an existence of cointegration. The first-difference ARDL is meanwhile used when there is no cointegration between variables. From the ARDL bound test as presented in Table 4, a cointegration is exist in model 2 (GDP leads to FDI), whereas there is no cointegration is found in model 1 (FDI increases GDP). Hence, the short-run analysis for model 1 is performed under the first difference ARDL, and the short-run estimation for model 2 uses the ECM.

Table 5 shows the estimation results of the short-run dynamic relationship under the first difference ARDL for model 1 and the ECM for model 2. In model 1, the coefficient of the lagged GDP is positive and significant, indicating that the past GDP brings positive impact to the current GDP. The coefficient of FDI also has positive and significant impact on GDP, as a 1\% increase in FDI will result in an increase in GDP of $0.0031 \%$. Since evidence for the impact of FDI is only found in the short-run dynamics, it could be an indication that Indonesian market is an attractive market for the short-term period.

2 Absolute value of $t$-statistic greater than absolute upper critical value at a $1 \%$ level of significance. 
Table 4 ARDL bound test result ( $F$ statistic and $t$ statistic)

\begin{tabular}{|c|c|c|c|c|c|c|}
\hline $\begin{array}{l}\text { Dependent } \\
\text { variables: } \\
\text { GDP }\end{array}$ & \multicolumn{6}{|c|}{$t$-statistic on the lagged dependent variable: -0.4799} \\
\hline \multirow{5}{*}{$\begin{array}{l}\text { Dependent } \\
\text { variables: } \\
\text { FDI }\end{array}$} & \multicolumn{6}{|c|}{$F$-statistic: 477.2555} \\
\hline & \multicolumn{6}{|c|}{$t$-statistic on the lagged dependent variable: -30.1062} \\
\hline & \multicolumn{4}{|c|}{ Pesaran et al. (2001) } & \multicolumn{2}{|c|}{ Narayan (2005) } \\
\hline & \multicolumn{2}{|c|}{$F$-test } & \multicolumn{2}{|c|}{$t$-test } & & \\
\hline & $I(0)$ & $I(1)$ & $I(0)$ & $I(1)$ & $I(0)$ & $I(1)$ \\
\hline $1 \%$ & 8.74 & 9.63 & -3.96 & -4.26 & 9.890 & 10.965 \\
\hline $5 \%$ & 6.56 & 7.30 & -3.41 & -3.69 & 7.080 & 7.910 \\
\hline $10 \%$ & 5.59 & 6.26 & -3.13 & -3.40 & 5.880 & 6.640 \\
\hline
\end{tabular}

Table 5 Estimated short-run coefficients and ECM results

\begin{tabular}{|c|c|c|c|}
\hline $\begin{array}{l}\text { Dependent } \\
\text { variable }\end{array}$ & Regressors & Coefficients & $t$-statistic \\
\hline \multirow{4}{*}{$\Delta \operatorname{lnGDP}$} & $C$ & 0.0393 & $4.1956^{* * *}$ \\
\hline & $\Delta \operatorname{lnGDP}{ }_{-1}$ & 0.3278 & $2.4619 * *$ \\
\hline & $\Delta \operatorname{lnGDP}_{-2}$ & -0.0728 & -0.5475 \\
\hline & $\Delta \operatorname{lnFDI}$ & 0.0031 & $3.7057 * * *$ \\
\hline \multirow{6}{*}{$\Delta \ln F D I$} & $C$ & -6.3796 & $-4.9074 * * *$ \\
\hline & $\Delta \ln \mathrm{FDI}_{-1}$ & -0.3504 & $-2.5345^{* *}$ \\
\hline & $\Delta \ln \mathrm{FDI}_{-2}$ & 0.0599 & 0.5003 \\
\hline & $\Delta \operatorname{lnGDP}$ & 76.7440 & $4.8328 * * *$ \\
\hline & $\Delta \operatorname{lnGDP}_{-1}$ & 42.1814 & $2.0373 * *$ \\
\hline & $\mathrm{ECT}_{-1}$ & -0.4406 & $-4.0898 * * *$ \\
\hline
\end{tabular}

Note: $* *, * * *$ indicates the significance level of $5 \%$, and $1 \%$.

In model 2, similar with the long-run dynamics, a rise in GDP will induce more FDI inflows. It shows that economic growth is one of necessary conditions for investors to invest in Indonesia. The coefficient of ECT in model 2 is negative and significant, implying that if there is a shock in the short-run, there will be an adjustment toward long-run equilibrium. The value of ECT is -0.44 indicates medium speed of adjustment toward equilibrium.

\subsection{Findings of diagnostic tests}

This section performs the diagnostic test to check that the residual of each model is uncorrelated and homoscedastic. Table 6 presents the results of diagnostic tests using the Breusch-Godfrey LM test, Breusch-Pagan-Godfrey

Table 6 Diagnostic tests results

\begin{tabular}{lcccccc}
\hline Dep. & \multicolumn{2}{c}{$\begin{array}{c}\text { Breusch-Godfrey } \\
\text { LM test }\end{array}$} & \multicolumn{2}{c}{$\begin{array}{c}\text { Breusch-Pagan- } \\
\text { Godfrey }\end{array}$} & \multicolumn{2}{c}{ J.B. } \\
\hline Variable & $F$-stat & Sig. & $F$-stat & Sig. & Stat. & Sig. \\
& 0.9092 & 0.4114 & 1.4346 & 0.2257 & 29.9728 & 0.0000 \\
& 2.9623 & 0.0637 & 1.3518 & 0.2576 & 0.1061 & 0.9483 \\
\hline
\end{tabular}

test, and Jarque-Bera (J.B) test. The results from BreuschGodfrey LM test and Breusch-Pagan-Godfrey confirm that there is no serial correlation and no heteroscedasticity in both models. From the Jarque-Bera test, it can be seen that the residuals from model 1 are not normally distributed, whereas the residuals from model 2 are normally distributed.

\subsection{Findings from the functional form test and the stability tests}

In checking whether the functional form of the model is well specified, the Ramsey RESET test is performed. The probability value from Ramsey RESET test for model 1 is 0.8091 , and for model 2 is 0.1045 . These results confirm the functional form of the models is well specified.

Stability tests are conducted in order to check a structural break of the series during the observed period. The possibility of structural break can be identified through the curves of CUSUM and CUSUMSQ. As shown in Fig. 3 (is displayed in Appendix), the residual plot of model 1 (Fig. 3 (a)) shows that none of the critical value (the red lines) are crossed by CUSUM and CUSUMQ curves. For model 2 (Fig. 3 (b)), the plot of CUSUM is well within the critical value, while the plot of CUSUMSQ is slightly crossing to the lower bound of the critical value in 2015. These statistics confirm that the ARDL results in this study are well-explained and no systematic change has been identified at a $5 \%$ level of significance.

\subsection{Findings from Granger causality}

After testing the cointegration relationship, one can check the causality relationship between the variables by using Granger causality test. As there is cointegration in the models, there is at least one direction Granger causality would appear. In Model 1, the null hypothesis that FDI does not Granger cause GDP cannot be rejected, as the probability of test statistic is 0.9917 , greater than the $10 \%$ level of significance. This finding indicates that FDI does not Granger caused GDP in the short-run.

In Model 2, the null hypothesis that GDP does not Granger cause FDI is rejected as the probability of test statistic is 0.0108 , which is lower than the $5 \%$ level of significance. In other word, GDP does Granger cause FDI. This means the past value of GDP significantly contribute to the prediction of the current value of FDI. Even in the presence of the past FDI in the country, GDP can lead to the movement of FDI. From these results, we can conclude that there 
is a short-run unidirectional causality running from GDP to FDI in Indonesia. This unidirectional causality is in line with Hsiao and Hsiao (2006) and Sarker and Khan (2020) although the countries under studies are different.

\section{Conclusion and policy implications}

This research examines the short-run and long-run dynamic and the causal relationship between GDP and FDI in Indonesia over the period 1970-2018. The empirical results from ARDL bounds testing show that there is a long-run relationship as well as a short-run relationship from GDP to FDI. The signs and values of Error Correction Term (ECT) and the corresponding t-statistic confirm the existence of a short-run relationship and the short-run disequilibrium for the FDI equation is converged to long-run equilibrium.

\section{References}

Adams, S. (2009) "Foreign Direct investment, domestic investment, and economic growth in Sub-Saharan Africa", Journal of Policy Modeling, 31(6), pp. 939-949.

https://doi.org/10.1016/j.jpolmod.2009.03.003

Agrawal, G. (2015) "Foreign Direct Investment and Economic Growth in BRICS Economies: A Panel Data Analysis", Journal of Economics, Business and Management, 3(4), pp. 421-424. https://doi.org/10.7763/joebm.2015.v3.221

Ali, N., Mingque, Y. (2018) "Does Foreign Direct Investment Lead to Economic Growth? Evidences from Asian Developing Countries", International Journal of Economics and Finance, 10(3), pp. 109-119. https://doi.org/10.5539/ijef.v10n3p109

Anwar, S., Nguyen, L. P. (2010) "Foreign direct investment and economic growth in Vietnam", Asia Pacific Business Review, 16(1-2), pp. 183-202.

https://doi.org/10.1080/10438590802511031

Balasubramanyam, V. N., Salisu, M., Sapsford, D. (1999) "Foreign direct investment as an engine of growth", The Journal of International Trade \& Economic Development, 8(1), pp. 27-40. https://doi.org/10.1080/09638199900000003

Borensztein, E., De Gregorio, J., Lee, J.-W. (1998) "How does foreign direct investment affect economic growth?", Journal of International Economics, 45(1), pp. 115-135. https://doi.org/10.1016/S0022-1996(97)00033-0

Brooks, C. (2014) "Modelling long-run relationships in finance", In: Brooks, C. (ed.) Introductory Econometrics for Finance, Cambridge University Press, Cambridge, UK, pp. 353-414. https://doi.org/10.1017/CBO9781139540872.009

Brown, R. L., Durbin, J., Evans, J. M. (1975) "Techniques for Testing the Constancy of Regression Relationships over Time", Journal of the Royal Statistical Society: Series B (Methodological), 37(2), pp. 149-163.

https://doi.org/10.1111/j.2517-6161.1975.tb01532.x
In addition, there is no evidence of long run relationship from FDI to GDP. However, in the short-run dynamic, it is found that FDI did significantly influence GDP as an increase in FDI results in an increase in GDP in the short run. The Granger causality test reveals the presence of the unidirectional causality running from GDP to FDI.

The policy implication of this research are firstly, policies in supporting a stable growth rate of GDP should be maintained in order to attract more FDI to Indonesia. Secondly, since the effect of FDI on GDP is only found in the short-run, government may develop relevant strategies to make Indonesian market also attractive for longrun investment. Thirdly, political stability is one of the important policies to have a stable macroeconomic position, as the 1998 tragedy did significantly hit FDI and GDP.

Chaudhry, N. I., Mehmood, A., Mehmood, M. S. (2013) "Empirical relationship between foreign direct investment and economic growth: An ARDL co-integration approach for China", China Finance Review International, 3(1), pp. 26-41. https://doi.org/10.1108/20441391311290767

Dickey, D. A., Fuller, W. A. (1981) "Likelihood Ratio Statistics for Autoregressive Time Series with a Unit Root", Econometrica, 49(4), pp. 1057-1072.

https://doi.org/10.2307/1912517

Disney, N. (1976) "Review of Accumulation on a World Scale: A Critique of the Theory of Underdevelopment, by Samir Amin", MERIP Reports, 51, pp. 21-24. https://oi.org/10.2307/3010910

Engle, R. F., Granger, C. W. J. (1987) "Co-Integration and Error Correction: Representation, Estimation, and Testing", Econometrica, 55(2), pp. 251-276. https://doi.org/10.2307/1913236

Fifeková, E., Nemcová, E. (2015) "Impact of FDI on Economic Growth: Evidence from V4 Countries", Periodica Polytechnica Social and Management Sciences, 23(1), pp. 7-14. https://doi.org/10.3311/PPso.7993

Firebaugh, G. (1992) "Growth Effects of Foreign and Domestic Investment", American Journal of Sociology, 98(1), pp. 105-130. https://doi.org/10.1086/229970

França, A., Rua, O. L. (2017) "Contributions of Absorptive Capabilities to Export Performance", Periodica Polytechnica Social and Management Sciences, 25(2), pp. 150-157. https://doi.org/10.3311/PPso.10281

Granger, C. W. J. (1969) "Investigating Causal Relations by Econometric Models and Cross-spectral Methods", Econometrica, 37(3), pp. $424-438$. https://doi.org/10.2307/1912791 
Granger, C. W. J. (2003) "Spurious Regressions in Econometrics", In: Baltagi, B. H. (ed.) A Companion to Theoretical Econometrics, Blackwell Publishing, Hoboken, NJ, USA, pp. 557-561. https://doi.org/10.1002/9780470996249.ch27

Hill, R. C., Griffiths, W. E., Lim, G. C. (2011) "Regression With TimeSeries Data: Nonstationary Variables: Learning Objectives", In: Principles of Econometrics, John Wiley \& Sons, Inc., Hoboken, NJ, USA, pp. 477-497.

Hsiao, F. S. T., Hsiao, M.-C. W. (2006) "FDI, exports, and GDP in East and Southeast Asia-Panel data versus time-series causality analyses", Journal of Asian Economics, 17(6), pp. 1082-1106. https://doi.org/10.1016/j.asieco.2006.09.011

Iamsiraroj, S. (2016) "The foreign direct investment-economic growth nexus", International Review of Economics \& Finance, 42, pp. 116-133.

https://doi.org/10.1016/j.iref.2015.10.044

Iamsiraroj, S., Ulubaşoğlu, M. A. (2015) "Foreign direct investment and economic growth: A real relationship or wishful thinking?", Economic Modelling, 51, pp. 200-213. https://doi.org/10.1016/j.econmod.2015.08.009

IMF (1998) "The Asian Crisis: Causes and Cures", Finance \& Development, 35(2). [online] Available at: https://www.imf.org/external/pubs/ft/ fandd/1998/06/imfstaff.htm [Accessed: 20 May 2020]

Indonesian Central Bank (2006) "Laporan Perekonomian Indonesia 2006" (Indonesia Economic Report 2006), [pdf] Bank Sentral Republik Indonesia. Jakarta, Indonesia. Available at: https://www.bi.go.id/id/ publikasi/laporan/Pages/lpi_2006.aspx [Accessed: 20 August 2020] (in Indonesian)

Johansen, S., Juselius, K. (1990) "Maximum Likelihood Estimation and Inference on Cointegration - with Applications to the Demand for Money", Oxford Bulletin of Economics and Statistics, 52(2), pp. $169-210$.

https://doi.org/10.1111/j.1468-0084.1990.mp52002003.x

Johansen, S. (1988) "Statistical analysis of cointegration vectors", Journal of Economic Dynamics and Control, 12(2-3), pp. 231-254. https://doi.org/10.1016/0165-1889(88)90041-3

Kersan-Škabić, I. (2015) "The Role of Investment Promotion Agencies in Attracting Foreign Direct Investments in the Southeast European Countries", Periodica Polytechnica Social and Management Sciences, 23(1), pp. 15-24. https://doi.org/10.3311/PPso.7966

Kwiatkowski, D., Philips, P. C. B., Schmindt, P., Shin, Y. (1992) "Testing the null hypothesis of stationarity against the alternative of a unit root: How sure are we that economic time series have a unit root?", Journal of Econometrics, 54(1-3), pp. 159-178. https://doi.org/10.1016/0304-4076(92)90104-Y

Lee, J., Strazicich, M. C. (2003) "Minimum Lagrange Multiplier Unit Root Test with Two Structural Breaks", The Review of Economics and Statistics, 85(4), pp. 1082-1089. https://doi.org/10.1162/003465303772815961

Li, X., Liu, X. (2005) "Foreign Direct Investment and Economic Growth: An Increasingly Endogenous Relationship", World Development, 33(3), pp. 393-407. https://doi.org/10.1016/j.worlddev.2004.11.001

Lucas, R. E. (1988) "On the mechanics of economic development", Journal of Monetary Economics, 22(1), pp. 3-42. https://doi.org/10.1016/0304-3932(88)90168-7
Narayan, P. K. (2005) "The saving and investment nexus for China: Evidence from cointegration tests", Applied Economics, 37(17), pp. 1979-1990. https://doi.org/10.1080/00036840500278103

Page, E. S. (1954) "Continuous Inspection Schemes", Biometrika, 41(1-2), pp. $100-115$. https://doi.org/10.2307/2333009

Pesaran, M. H., Shin, Y., Smith, R. J. (2001) "Bounds testing approaches to the analysis of level relationships", Journal of Applied Econometrics, 16(3), Special Issue: In Memory of John Denis Sargan 1924-1996: Studies in Empirical Macroeconometrics, pp. 289-326. https://doi.org/10.1002/jae.616

Phillips, P. C. B., Perron, P. (1988) "Testing for a unit root in time series regression", Biometrika, 75(2), pp. 335-346. https://doi.org/10.1093/biomet/75.2.335

Rahman, M. M., Kashem, M. A. (2017) "Carbon emissions, energy consumption and industrial growth in Bangladesh: Empirical evidence from ARDL cointegration and Granger causality analysis", Energy Policy, 110, pp. 600-608 https://doi.org/10.1016/j.enpol.2017.09.006

Romer, P. M. (1986) "Increasing Returns and Long-Run Growth", Journal of Political Economy, 94(5), pp. 1002-1037. https://doi.org/10.1086/261420

Roy, S., Mandal, K. K. (2012) "Foreign Direct Investment and Economic Growth: An Analysis for Selected Asian Countries", Journal of Business Studies Quarterly, 4(1), pp. 15-24. [online] Available at: http://citeseerx.ist.psu.edu/viewdoc/ download?doi=10.1.1.652.4730\&rep=rep1\&type $=$ pdf $\quad[$ Accessed: 20 August 2020]

Sarker, B., Khan, F. (2020) "Nexus between foreign direct investment and economic growth in Bangladesh: an augmented autoregressive distributed lag bounds testing approach", Financial Innovation, 6, Article number: 10. https://doi.org/10.1186/s40854-019-0164-y

Solow, R. M. (1956) "A Contribution to the Theory of Economic Growth", The Quartely Journal of Economics, 70(1), pp. 65-94. https://doi.org/10.2307/1884513

The Asean Post Team (2019) "ASEAN pushing global GDP growth", The Asean Post, [online] 23 October 2019. Available at: https:// theaseanpost.com/article/asean-pushing-global-gdp-growth [Accessed: 08 May 2020]

UNCTAD (2019) "Global foreign direct investment slides for third consecutive year", UNCTAD, [online] 12 June 2019. Available at: https:// unctad.org/en/pages/newsdetails.aspx? OriginalVersionID=2118 [Accessed: 16 May 2020]

World Development Indicator (2019) "World Bank Open Data", [online] Availabl at: https://data.worldbank.org/ [Accessed: 20 August 2020]

Zhang, Y., Zhang, S. (2018) "The impacts of GDP, trade structure, exchange rate and FDI inflows on China's carbon emissions", Energy Policy, 120, pp. 347-353. https://doi.org/10.1016/j.enpol.2018.05.056 


\section{Appendix}
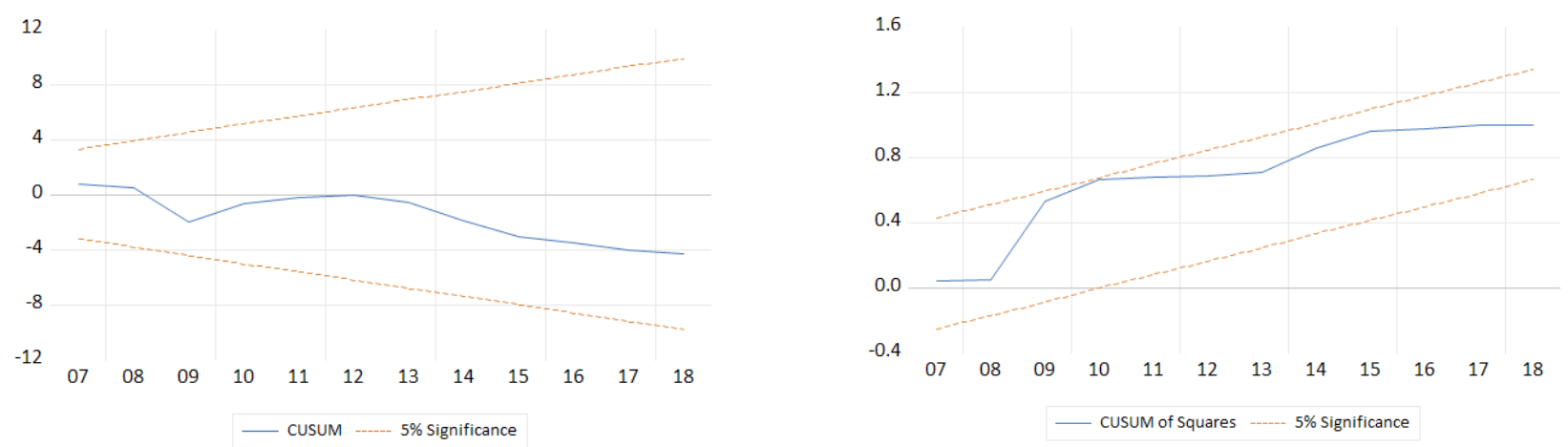

(a)
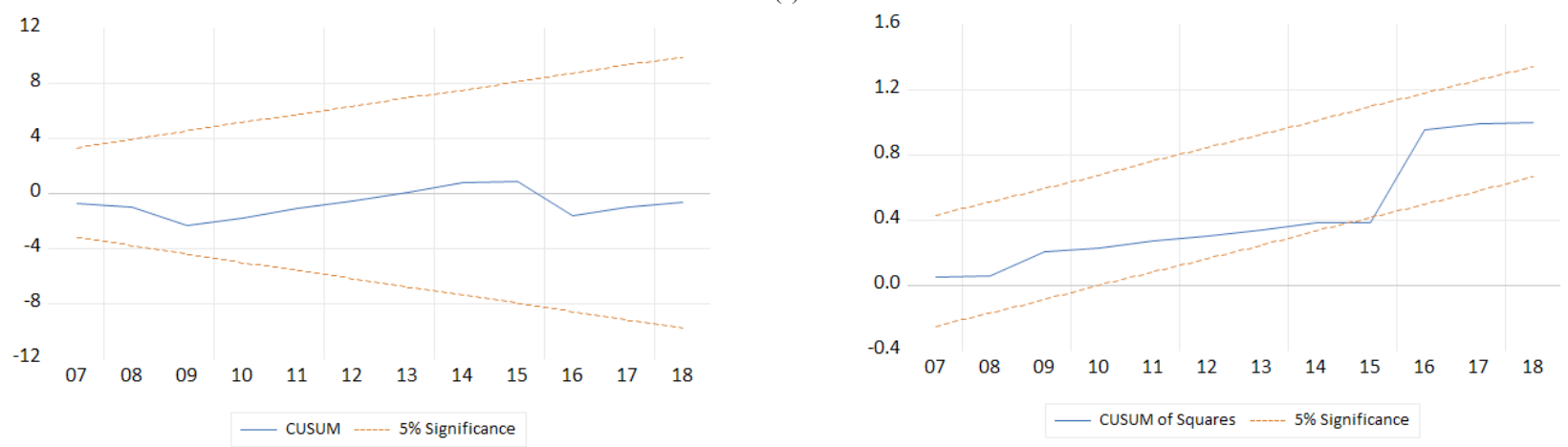

(b)

Fig. 3 Plot of CUSUM and CUSUM of Squares for model 1 (a) and model 2 (b) 